\title{
Prevalence of depression and associated factors among haemodialysis patients at government and private hospitals in Addis Ababa
}

\author{
Betelehem Endris', Mahlet Fikreyesus', Tadele Amare ${ }^{2}$ \\ 'Department of Psychiatry, Amanuel Mental Specialized Hospital, Addis Ababa, Ethiopia; ${ }^{2}$ Department of Psychiatry, College of Medicine \\ and Health Sciences, University of Gondar, Gondar, Ethiopia.
}

\section{ABSTRACT}

Background: Depression is the most common psychiatric disorder in long-term dialysis patients and a risk factor for morbidity and mortality. Depression in haemodialysis patients has been persistently underdiagnosed and undertreated. There are negative consequences for the individual in respect of family roles, work competence, sexual function and mobility. We aimed to assess the prevalence of depression and associated factors among haemodialysis patients at government and private hospitals in Addis Ababa, Ethiopia.

Methods: A cross-sectional study was conducted from May to June 2017 at government and private hospitals in Addis Ababa.The Patient Health Questionnaire (PHQ-9) was used to assess depression and the Oslo Social Support Scale (OSLO-3) was employed to assess social support.

Results: A total of 426 patients were included. The mean age was $45.6 \pm 15.0$ years and $65.3 \%$ were male. The prevalence of depression was 60.3\%. Factors associated with depression included being female (adjusted odds ratio (OR) 1.7), comorbid medical illness (OR 1.9), poor social support (OR 3.8), and medium income (OR 2.8).

Conclusions: Depression is very common among haemodialysis patients in Ethiopia and should always be considered in their management. Being female, having poor social support, being subject to other medical illnesses and a medium level of income were risk factors for depression. Future studies should assess the adequacy of dialysis as under-treatment may contribute to the high rate of depression observed.

Keywords: Depression; end-stage renal failure; haemodialysis.

\section{INTRODUCTION}

Depression is a common mental disorder that presents with depressed mood, loss of interest or pleasure, decreased energy, feelings of guilt or low self-worth, disturbed sleep or appetite, and poor concentration. Globally, it is a major public health problem which mostly manifests in later adulthood, with the lifetime risk ranging from 10-25\% for women and 5-12\% for men [I-3].

In patients with end-stage renal disease (ESRD), depression is the most common psychiatric illness [4], with an estimated prevalence ranging from 25-33\% [5]. In patients on chronic dialysis, the suicide risk is fifteen times greater than that of the general population $[6,7]$.

The rate of depression in dialysis patients using the Centre for Epidemiological Studies Depression Screening Index (CES-D) was 68\% in the United Kingdom [8], 1924\% in Washington DC [4], and 26-38.6\% in China [9]. In Canada, the estimated prevalence of depression was $39.3 \%$ in patients with ESRD [10]. The prevalence in Brazil was 42.7\% [ I I], in Saudi Arabia 83.5\% [12], Israel 43.7\% [13], Serbia 49.1\% [14] and 40.7\% in Iran [15]. In

Received 03 May 20 8; accepted 09 October 20 I8; published 06 November 2018 
Africa, the prevalence of depression among ESRD patients was 19-24\% in Egypt [16] and 34\% in Morocco [17].

Many factors are associated with depression in haemodialysis patients, including older age, lower haemoglobin and hospitalization [6]. Changing family roles, reduced work competence, fear of death and dependence on treatment may exacerbate feelings of loss of control and adversely affect quality of life [18].

We assessed the prevalence of depression and associated factors among patients on haemodialysis at hospitals In Addis Ababa, to provide useful data for mental health professionals, nephrologists and other staff members caring for these patients.

\section{METHODS}

A cross-sectional study was conducted from April to May 2017 in Addis Ababa, the capital of Ethiopia. The population of the city is estimated at approximately 3.1 million by the Central Statistics Agency. The participants were adult patients with ESRD receiving regular haemodialysis treatments at I I centres in the city. Two of these are government centres and nine are privately owned. The usual schedule of dialysis treatment in stable patients comprises sessions of three to four hours, two to three times per week. The cost of treatment is borne by the patient and their families.

Face-to-face interviews were conducted and used closedended and open-ended questions as well as standardized questionnaires. The Patient Health Questionnaire (PHQ-9) [19] produces scores which range from 0 to 27 . These can be interpreted as indicating minimal depression (score 0-4), mild depression (5-9), moderate depression ( 10-14), moderately severe depression (15-19) and severe depression (20-27). The Oslo Social Support Scale (OSLO-3) produces scores which range from 3 to 14 [20]. It has three classifications: poor social support (score 3-8), moderate social support (9-|I) and strong social support (|2-14). Data were also collected on factors such as substance use (of tobacco, alcohol, khat). After piloting, the questionnaires were modified and translated into the Amharic language so as to be understood by all participants. Training was provided to all study personnel.

Depression was diagnosed based on a score of $\geq 10$ on the PHQ-9 depression scale. Current substance use was defined as consuming the substance at least once within the previous month. Social support was graded according to the OSLO-3 scale.

Data were coded and entered into EPI info version 3.5.3 [2I], then exported to SPSS version 20 [22]. We generated descriptive statistics to describe the variables of interest and to estimate the prevalence of depression. Bivariate and multivariate logistic regressions were used to identify factors associated with depression. The strength of association was estimated using crude and adjusted odds ratios (COR and $\mathrm{AOR}$ ) with 95\% confidence intervals (Cl). Variables associated with outcomes at the $p<0.2$ level in the bivariate regression were included in multivariate regression models. Variables that were significant at the $p<0.05$ level in the multivariate logistic regression are reported as independent factors associated with the outcome.

\section{Ethical considerations}

Ethical clearance was obtained from the Institutional Review Board of the College of Medicine and Health Sciences, University of Gondar, and from Amanuel Mental Specialized Hospital and Addis Ababa Health Bureau Ethical Review Committee. Permission was also obtained from each participating hospital.

\section{RESULTS}

Of the 435 patients eligible for the study, the response rate was 426 (98\%). Table I summarizes the demographic characteristics of the study population. Of these participants, 278 (65\%) were male. The mean age was $45.6 \pm 15.0$ years. Most were Orthodox Christians (52.3\%) and married (53.3\%). One-third had college-level education and $45.3 \%$ were unemployed.

Table 2 summarizes some clinical factors in our study population. Three-quarters had comorbid medical illness, with hypertension and diabetes the most common, and approximately $40 \%$ had been on dialysis for two or more years.

Concerning psychosocial factors, 20 I (47.2\%), I 45 (34.0\%), and 80 (18.8\%) participants had poor, moderate, and strong social support, respectively. There was a history of substance use in 18 (4.5\%). Of these, 12 took alcohol and 6 had a history of chewing khat.

The overall prevalence of depression was 60.3\% (I58 males and 99 females). There were 109 participants (25.6\%) who had minimal depression, 60 (14.1\%) with mild depression, 102 (23.9\%) with moderate depression, 87 (20.4\%) with moderately severe depression and 68 (16.0\%) with severe depression. The bivariate analyses of factors associated with depression are summarized in Table 3.

Table 4 summarizes the factors associated with depression on multivariate logistic regression analysis. The odds of developing depression among patients with medium income were nearly three times those of patients with a 


\begin{tabular}{|c|c|c|c|}
\hline & & Frequency & $\%$ \\
\hline \multirow[t]{2}{*}{ Sex } & Male & 278 & 65.3 \\
\hline & Female & 148 & 34.7 \\
\hline \multirow[t]{3}{*}{ Age } & |8-24 & 39 & 39 \\
\hline & $25-49$ & 210 & 210 \\
\hline & $\geq 50$ & 177 & 177 \\
\hline \multirow[t]{4}{*}{ Education level } & No formal education & 51 & 12.0 \\
\hline & Primary level & 92 & 21.6 \\
\hline & Secondary level & 140 & 32.9 \\
\hline & College/above & 143 & 33.6 \\
\hline \multirow[t]{4}{*}{ Religion } & Orthodox & 223 & 52.3 \\
\hline & Protestant & 78 & 18.3 \\
\hline & Catholic & 18 & 4.2 \\
\hline & Muslim & 107 & 25.1 \\
\hline \multirow[t]{3}{*}{ Marital status } & Single & 143 & 33.6 \\
\hline & Married & 227 & 53.3 \\
\hline & Other" & 56 & 13.1 \\
\hline \multirow[t]{6}{*}{ Occupation } & Private & 76 & 17.8 \\
\hline & Government & 42 & 9.9 \\
\hline & Unemployed & 193 & 45.3 \\
\hline & Housewife & 44 & 10.3 \\
\hline & Student & 26 & 6.1 \\
\hline & Retired & 45 & 10.6 \\
\hline \multirow[t]{3}{*}{$\begin{array}{l}\text { Monthly income } \\
\text { (Ethiopian birr" }\end{array}$} & $<735$ & 259 & 60.8 \\
\hline & $735-1176$ & 88 & 20.7 \\
\hline & $>1176$ & 79 & 18.5 \\
\hline \multirow[t]{2}{*}{ Residence } & Rural & 150 & 35.2 \\
\hline & Urban & 276 & 64.8 \\
\hline
\end{tabular}

higher level of income. The odds ratio among patients with comorbid medical illness was close to 2, as was the odds ratio for females. The odds ratio among patients who had poor social support was close to 4. Substance use, age, employment, marital status, religion, family history of mental illness and urban/rural residence were not independently associated with depression.

\section{DISCUSSION}

The prevalence of depression in our study was 60.3\%, about three times higher than the prevalence in the general

\begin{tabular}{|c|c|c|c|}
\hline & Categories & Frequency & $\%$ \\
\hline Comorbid medical & Yes & 323 & 75.8 \\
\hline illness & No & 103 & 24.2 \\
\hline \multirow[t]{2}{*}{ Hypertension } & Yes & 258 & 60.6 \\
\hline & No & 168 & 39.4 \\
\hline \multirow[t]{2}{*}{ Diabetes mellitus } & Yes & 144 & 33.8 \\
\hline & No & 282 & 66.2 \\
\hline \multirow[t]{2}{*}{ Heart failure } & Yes & 17 & 4.0 \\
\hline & No & 409 & 96.0 \\
\hline \multirow[t]{2}{*}{ Epilepsy } & Yes & 6 & 1.4 \\
\hline & No & 420 & 98.6 \\
\hline \multirow[t]{4}{*}{$\begin{array}{l}\text { Length of time on } \\
\text { dialysis }\end{array}$} & I-6 months & 149 & 35.0 \\
\hline & $7-12$ months & 56 & 13.1 \\
\hline & I-2 years & 45 & 10.6 \\
\hline & $>2$ years & 176 & 41.3 \\
\hline \multirow[t]{2}{*}{$\begin{array}{l}\text { Family history of } \\
\text { mental illness }\end{array}$} & Yes & 17 & 4.0 \\
\hline & No & 409 & 96.0 \\
\hline
\end{tabular}

population [3] and also much higher than that reported for dialysis patients in many other countries. However, it was lower than the prevalence reported in some studies from Saudi Arabia (83.5\%) and the UK (68\%) [12,8].

Regarding the associated factors, females were about twice as likely to have depression than males. This is similar to the findings in other studies [9]. Possible reasons for this might include a genetic predisposition to develop depression, hormonal factors and higher levels of stress. We found that having a medium level of income was associated with depression. Inadequate income is a common problem among patients on dialysis and may be linked to the difficulty in maintaining employment, reduced physical function and energy, and diminution of cognitive skills $[4,18]$. Patients who had other medical illnesses, especially hypertension and diabetes, were more likely to have depression. This is similar to findings reported from Egypt [16]. Patients who had poor social support were about four times more likely to have depression.

Our study had several limitations. A cross-sectional study design was used, and we could therefore report associations only between possible risk factors and depression, and not cause-and-effect relationships. The delivery of adequate dialysis was also not evaluated in our study. Under-dialysis 
Table 3. Bivariate logistic regression of factors associated with depression among haemodialysis patients in Addis Ababa.

\begin{tabular}{|c|c|c|c|c|c|}
\hline & \multirow[t]{2}{*}{ Category } & \multicolumn{2}{|c|}{ Depression } & \multirow[t]{2}{*}{$\operatorname{COR}(95 \% \mathrm{Cl})$} & \multirow[t]{2}{*}{$\mathrm{P}$-value } \\
\hline & & Yes (257) & No (169) & & \\
\hline \multirow[t]{2}{*}{ Sex } & Male & 158 & 120 & I & \\
\hline & Female & 99 & 49 & $1.5(1.01,2.3)$ & 0.01 \\
\hline \multirow[t]{3}{*}{ Age } & | 8-24 & 25 & 14 & I & \\
\hline & $25-49$ & 122 & 88 & $0.8(0.6,2.3)$ & 0.42 \\
\hline & $\geq 50$ & 110 & 67 & $0.9(0.8,3.4)$ & 0.44 \\
\hline \multirow[t]{4}{*}{ Education } & No formal & 36 & 15 & I.8 $(0.9,3.6)$ & 0.12 \\
\hline & Primary & 58 & 34 & $1.3(0.7,2.2)$ & 0.25 \\
\hline & Secondary & 82 & 58 & I.0 (0.6, I.7) & 0.31 \\
\hline & College/above & 81 & 62 & । & \\
\hline \multirow[t]{4}{*}{ Religion } & Orthodox & 144 & 79 & । & \\
\hline & Protestant & 37 & 41 & I.6 $(0.4,3.6)$ & 0.76 \\
\hline & Catholic & 11 & 7 & $0.1(0.02,2.1)$ & 0.26 \\
\hline & Muslim & 65 & 42 & $0.8(0.5,3.1)$ & 0.33 \\
\hline \multirow[t]{3}{*}{ Marital status } & Married & 137 & 90 & । & \\
\hline & Single & 96 & 47 & $1.3(0.9,3.2)$ & 0.53 \\
\hline & Separated/divorced/widowed & 24 & 32 & $0.5(0.3,1.5)$ & 0.31 \\
\hline \multirow[t]{6}{*}{ Jobs } & Private & 36 & 40 & $1.2(0.5,2.5)$ & 0.26 \\
\hline & Government & 22 & 20 & $1.9(1.1,3.4)$ & 0.07 \\
\hline & Unemployed & 124 & 69 & $2.1(0.9,4.6)$ & 0.34 \\
\hline & Housewife & 29 & 15 & $2.0(0.8,5.2)$ & 0.27 \\
\hline & Student & 17 & 9 & $2.0(0.9,4.3)$ & 0.69 \\
\hline & Retired & 29 & 16 & । & \\
\hline \multirow{3}{*}{$\begin{array}{l}\text { Monthly income } \\
\text { (Ethiopian birr) }\end{array}$} & $<735$ & 160 & 99 & $2.1(1.2,3.5)$ & 0.1 \\
\hline & $735-1176$ & 63 & 25 & $3.3(1.7,6.3)$ & 0.04 \\
\hline & $>1176$ & 34 & 45 & I & \\
\hline \multirow[t]{2}{*}{ Residence } & Rural & 90 & 60 & । & \\
\hline & Urban & 167 & 109 & I.I $(0.7,3.6)$ & 0.32 \\
\hline \multirow[t]{2}{*}{ Comorbid illness } & No & 53 & 50 & I & \\
\hline & Yes & 204 & 119 & $1.6(1.3,2.5)$ & 0.13 \\
\hline \multirow[t]{2}{*}{ Hypertension } & No & 73 & 95 & । & \\
\hline & Yes & 184 & 74 & $3.2(0.9,4.5)$ & 0.42 \\
\hline \multirow[t]{2}{*}{ Diabetes mellitus } & No & 159 & 123 & I & \\
\hline & Yes & 98 & 46 & $1.6(1.0,2.5)$ & 0.18 \\
\hline \multirow[t]{4}{*}{ Length of time on dialysis } & I-6 months & 86 & 63 & I & \\
\hline & $7-12$ months & 30 & 26 & $0.8(0.4,1.5)$ & 0.51 \\
\hline & I-2 years & 34 & 11 & $2.2(1.0,4.8)$ & 0.11 \\
\hline & $>2$ years & 107 & 69 & I.I $(0.7,1.7)$ & 0.46 \\
\hline \multirow[t]{2}{*}{ Family history of mental illness } & Yes & 7 & 10 & $0.4(0.3,2.9)$ & 0.37 \\
\hline & No & 250 & 159 & । & \\
\hline \multirow[t]{3}{*}{ Social support } & Poor & 148 & 53 & $3.2(1.8,5.5)$ & 0.06 \\
\hline & Moderate & 72 & 73 & I.I $(0.6,1.9)$ & 0.21 \\
\hline & Strong & 37 & 43 & I & \\
\hline \multirow[t]{2}{*}{ Khat use } & Yes & 4 & 2 & I.3 $(0.8,2.1)$ & 0.81 \\
\hline & No & 253 & 167 & । & \\
\hline \multirow[t]{2}{*}{ Alcohol use } & Yes & 3 & 9 & $0.2(0.1,1.2)$ & 0.52 \\
\hline & No & 254 & 160 & I & \\
\hline
\end{tabular}


Table 4. Multivariate analysis of baseline factors associated with depression among haemodialysis patients in Addis Ababa.

\begin{tabular}{lccc|}
\hline & HR & $95 \% \mathrm{Cl}$ & P-value \\
\hline Female sex & 1.70 & $1.01,2.88$ & 0.03 \\
Monthly income & 2.79 & $1.38,5.60$ & 0.02 \\
Comorbid illness & 1.87 & $1.15,3.05$ & 0.03 \\
Poor social support & 3.75 & $2.11,6.65$ & $<0.01$ \\
\hline
\end{tabular}

may well have contributed to the high rate of depression we observed as treatments were funded by patients and their families. Financial constraints are likely to have resulted in fewer treatment sessions being delivered per week, and in limited access to important medications such as intravenous iron and erythropoietin.

In conclusion, there is a high prevalence of depression among Ethiopian patients with ESRD who are treated with chronic haemodialysis and it is important to consider this in the holistic management of our patients. Female patients, those with poor social support, with additional comorbid illnesses, and those with medium and lower levels of income may be at greater risk for depression. We recommend that screening for depression be integrated into the routine care of patients who present with ESRD and in those already on dialysis. Future studies should formally assess the adequacy of the dialysis delivered, as undertreatment may contribute to the high rate of depression observed.

\section{Acknowledgments}

The authors are indebted to Amanuel Mental Specialized Hospital and the University of Gondar for funding this research. Our appreciation goes to all study personnel and study participants.

\section{Participating centres/hospitals}

Government centres: St Paul's Hospital Millennium Medical College and Zewditu Memorial Hospital.

Private centres: Tom Higher Clinic, Betel Hospital, St Gabriel General Hospital, Hallelujah General Hospital, Myungsung Christian Medical Hospital, Hayat Hospital, Sante Higher Clinic, Aynalem Hospital and Tsegereda Higher Clinic.

\section{REFERENCES}

I. Sadock B, Ruiz P. Kaplan \& Sadock's Synopsis of Psychiatry: Behavioral sciences: Walters Kluwer; 2015.

2. Van Melle JP, De Jonge P, Spijkerman TA, Tijssen JG, Ormel J, Van Veldhuisen DJ, et al. Prognostic association of depression following myocardial infarction with mortality and cardiovascular events: a meta-analysis. Psychosom Med. 2004; 66(6):8I4-822.
3. Braveman P, Starfield B, Geiger HJ. World Health Report 2000: How it removes equity from the agenda for public health monitoring and policy. BMJ. 200I; 323:678-679.

4. Kimmel PL, Peterson RA. Depression in patients with end-stage renal disease treated with dialysis: has the time to treat arrived? Clin J Am Soc Nephrol. 2006; I (3):349-352.

5. Katon WJ, Lin EH, Von Korff M, Ciechanowski P, Ludman EJ, Young B, et al. Collaborative care for patients with depression and chronic illnesses. N Engl J Med. 20 I0; 363(27):26 I I-2620.

6. Young BA, Von Korff M, Heckbert SR, Ludman EJ, Rutter C, Lin EH, et al. Association of major depression and mortality in Stage 5 diabetic chronic kidney disease. Gen Hosp Psychiatry. 2010; 32(2): $119-124$.

7. Kimmel P. Depression as a mortality risk factor in hemodialysis patients. Int J Artif Organs. 1992; I (12):697-700.

8. Chilcot J, Wellsted D, Silva-Gane D, Farrington K. Depression on dialysis. Nephron Clin Pract. 2008; I08(4):c256-264.

9. Hou Y, Li X, Yang L, Liu C, Wu H, Xu Y, et al. Factors associated with depression and anxiety in patients with end-stage renal disease receiving maintenance hemodialysis. Int Urol Nephrol. 2014; 46(8): $1645-1649$.

10. Weisbord SD. Patient-centered dialysis care: depression, pain, and quality of life. Semin Dial. 20 I6; 29(2): I 58- 164.

II. Teles F, Azevedo VFD, Miranda CT, Miranda MPM, Teixeira MC, Elias RM. Depression in hemodialysis patients: the role of dialysis shift. Clinics. 2014; 69(3):198-202.

12. AIDukhayel A. Prevalence of depressive symptoms among hemodialysis and peritoneal dialysis patients. Int J Health Sci Res. 2015; 9(1):9-16.

13. Yucedal C, Olmez N, Gezen G, Celik F, Altindag A, Yilmaz M, et al Depression in dialysis patients. EDTNA-ERCA Journal. 2003;29(3): |5|-|55.

14. Trbojević-Stanković J, Stojimirović B, Bukumirić Z, Hadžibulić E, Andrić $B$, Đorćević $V$, et al. Depression and quality of sleep in maintenance hemodialysis patients. Srp Arh Celok Lek. 20 I 4; 142(7-8):437-443.

15. Ossareh S, Tabrizian S, Zebarjadi M, Joodat RS. Prevalence of depression in maintenance hemodialysis patients and its correlation with adherence to medications. Iran J Kidney Dis. 20।4; 8(6):467.

16. Ibrahim S, El Salamony O. Depression, quality of life and malnutrition-inflammation scores in hemodialysis patients. Am J Kidney Dis. 2008; 28(5):784-791.

17. El Filali A, Bentata Y, Ada N, Oneib B. Depression and anxiety disorders in chronic hemodialysis patients and their quality of life: a cross-sectional study about 106 cases in the northeast of Morocco. Saudi J Kidney Dis Transpl. 2017; 28:34I-348.

18. Chen C-K, Tsai Y-C, Hsu H-J, Wu I-W, Sun C-Y, Chou C-C, et al. Depression and suicide risk in hemodialysis patients with chronic renal failure. Psychosomatics. 2010; 5 I (6):528-. e6.

19. Gilbody S, Richards D, Brealey S, Hewitt C. Screening for depression in medical settings with the Patient Health Questionnaire (PHQ): a diagnostic meta-analysis. J Gen Intern Med. 2007; 22( I I): 1596- 1602.

20. Abiola T, Udofia O, Zakari M. Psychometric properties of the 3-item Oslo Social Support scale among clinical students of Bayero University Kano, Nigeria. Malays J Psychiatry. 201 3; 22(2):32-4I.

21. Epi Info ${ }^{\mathrm{TM}}$, a database and statistics program for public health professionals. CDC, Atlanta, GA, USA, 2011.

22. Nie N, Hull C, Bent D. IBM Statistical Package for the Social Sciences (version 20). Chicago, IL, 20II. 